\title{
Natural biological systems - the key to success of modern agriculture
}

\author{
Ivashchenko A. 0. \\ Professor, academician of NAAS \\ Ivashchenko A. A. \\ Dr. S.-G. Sciences, \\ Naidenov V. G. \\ candidate. S.-G. of Sciences, \\ Institute of bioenergy crops and sugar beet NAAS \\ Institute of plant protection NAAS \\ Askaniisk State agricultural experimental station of Institute of irrigatedagriculture NAAS
}

The purpose. Analysis and assessment of anthropogenic fluctuations as a result of economic activities of domestic landowners and producers of agricultural products in the world. Methods. Analysis, consolidation, simulation. Results. Modern state of intensive agriculture is analyzed; assessment of the most productive natural biological systems is made. Methodology of approaches to magnification of environmental acceptance of modern systems of farming agriculture is specified. Conclusions. To analyze in more details all component ingredients of interaction of the alive and nonliving nature and creatively implement the determined principles into practice of modern agrarian production. To create highly productive agro-ecosystems which do not erode and do not contaminate environment.

Key words: biological efficiency, intensive techniques, tropical forests, ecology, biological diversity.

On the planet of agricultural use, the result of economic activity for the construction of cities, roads, airfields, industrial plants, warehouses of industrial waste annually seized the arable land from 14 to 16 million hectares.

For cultivation of agricultural plants need arable land, which formed from natural biocenoses. In the process of such transformation of the natural species of diversity, will replaced by one of cultivation of crops: corn, wheat, soy, or other. As result of this antropo changes in species diversity, especially plants, decreases in tens times.

Decreases and species diversity of soil biota. In certain systems of mutual relations with every kind of plants green, co-exist dozens of types of specialized microorganisms that forms its own unique dynamic living systems. Systena plants - producers leads to the disappearance and organisms konsument.

Per hectare humid tropical forest of South America it is easily, possible to count more than 750 species of trees only, without taking into account other forms of plants: lianas, herbs, shrubs. Biological productivity of tropical forests traditionally .xceed $3.0-3.5 \mathrm{~kg} / \mathrm{m}^{2}$ of dry matter per year.

For comparison, the sowing of winter wheat (Triticum aestivum) yield of $10 \mathrm{t} / \mathrm{ha}$ of grain forms of $\mathrm{m} 2$ of 2.07 $\mathrm{kg}$ of dry matter.To illustrate the situation to the analysis of mineral substances that are necessary to learn to plant wheat for the formation of 10t/ha of grain and appropriate amount of by-products): $350 \mathrm{~kg}$ nitrogen compounds, phosphorus compounds - 135кг, compounds of potassium - $260 \kappa r$. Total $745 \kappa г$ with the area of one hectare.

Nitrogen compounds in the first year after their introduction into the soil of cultural plants used by $50-60 \%$ and phosphorus compounds by $20-25 \%$, potassium compounds for $60-70 \%$ of the value of their input.In ecosystem of tropical rainforest, biogenic compounds are constantly in circulation and their alienation is not happening.The modeling of tropical forests in the temperate climatic zone of nemola, however, the use of the principles vmod componets tropical biocenoses will allow to develop highly productive crops and do not destroy do not pollute the environment.

The growth of the world population requires ever more food. The possibility of expansion of arable land will depleted by the middle of the 21st century. Most of these vacant lands are in Africa[1]. The process of expansion of arable land coincides with the simultaneous withdrawal of such lands from their intended use. Some of them as result of active erosion processes are unsuitable for growing agricultural products. Considerable areas as result of improper irrigation system received the secondary alkalinization and reduced their level of fertility. Every year large areas have to derived from agricultural use for construction of cities, roads, airfields, industrial plants, warehouses of industrial waste. Such annual losses of arable land are between 14 and 16 million hectares. [2].As a result of "green revolution" since the 70-ies of the last century began the era of intensification of agricultural production. Intensive were created varieties and hybrids that are 
able to form significant yields of corn, soybeans and other crops on arable land with high levels of fertility effective and reliable protection against harmful organisms.

The cultivation of agricultural products beyond the traditional approaches of intensification carries a number of contradictions that are difficult or impossible to solve in the current coordinate system of production. Primarily for agricultural production of the desired surface area of land in the respective climatic zones of the planet [3].

For cultivation of agricultural plants need arable land, which formed from natural biocenoses. In the process of such transformation of species diversity, primarily green plants will destroyed and he will replaced by one of cultivation of crops: corn, wheat, soy, or other. As result of this antropo changes in species diversity, especially plants, is reduced more than tenfold[4].Decreases and species diversity of soil biota. In certain systems of mutual relations with every kind of green plants, co-exist dozens of types of specialized microorganisms that forms its own unique dynamic living systems [5].

Modern biological studies of the interaction of organisms in natural biocenoses prove complex and ambiguous relationships of different systematic position of the organism's higher green plants, fungi, bacteria, algae and other life forms. At the heart of such living systems always function, green plants are the producers of organic matter and the accumulated energy of the sun to all living things complex. The greatest concentration of these life forms are concentrated in ritali area roots of green plants[6]. Plants capable of carrying out the processes of photosynthesis and maturea on juvenile stages of the organogenesis from 30 to $50 \%$ of the volume of their synthesized organic substances, is removed via root hairs in ritaln area and are a food source and obtaining energy by ground systems of living organisms[7].With every kind of green plants as producers of organic matter in various forms of symbiosis, exist from 20 to 300 species of living organisms. Therefore, the destruction on the territory of wild green plants in the process antropo its transformation into arable land and leads to the death of complexes of living organisms consuments who have had them with trophic linkages, and carried out biochemical transformation of organic compounds in the soil[8].

Low species diversity of plants, almost one species of cultural plants in the field, leads to loss of ability of self-regulation and maintain homeostasis created an artificial biological system - agriculture. Such a function takes on people. Artificial biological systems - agriculture is not able to maximize the use and environmental factors[9]. The level of productivity man-made biological systems - agriculture, traditionally or inferior, or only approaches the level of productivity of the natural systems in the region. The most productive biological systems: tropical forests have the highest species diversity and completeness of use environmental factors[10]. Per hectare humid tropical forest of South America it is easily, possible to count more than 750 species of trees only, without taking into account other forms of plants: lianas, herbs, shrubs.

Biological productivity of tropical forests traditionally exceed $3.0-3.5 \mathrm{~kg} / \mathrm{m}^{2}$ of dry matter per year[11].The crops of cultivated plants on arable lands even at the maximum intensification of cultivation technologies only approach to such indicators of biological productivity. Such indicators, taking into account not only economically valuable part of the crop, and all the dry biological mass, which can be synthesized over a year on the area of a square meter of arable land is traditionally only occasionally exceed $2.0-2.5 \mathrm{~kg}$ even in the tropics[12]. For comparison, the sowing of winter wheat (Triticum aestivum) yield of $10 \mathrm{t} / \mathrm{ha}$ of grain forms of $\mathrm{m}^{2}$ of $2.07 \mathrm{~kg}$ of dry matter.

Increasing level of intensification of agricultural production through the use of new varieties and hybrids and modern technologies of cultivation of agricultural crops by increasing norms of mineral fertilizers and application of pesticides and irrigation leads not only to increased biological productivity of crops, and considerable pollution of natural biological systems[13]. Modern varieties and hybrids of agricultural crops, such as cereals and legumes, vegetable, berry, and others, are able to show high biological productivity only under the condition of high level of soil effective fertility. For its formation in the first place applied high norms of mineral fertilizers[14].

To illustrate the situation to the analysis of mineral substances, which are necessary to learn to plant wheat for the formation of 10t/ha of grain and appropriate amount of by-products): $350 \mathrm{~kg}$ nitrogen compounds, phosphorus compounds $-135 \kappa r$, compounds of potassium $-260 \kappa г$. Total $745 \kappa r$ with the area of one hectare. However, the introduction of the arable land is based on the maximum rate of assimilation of macronutrients by plants for the formation of such a grain crop requires 583кг nitrogen compounds, phosphorus compounds $540 \mathrm{\kappa r}$, compounds of potassium $371 \kappa r$. Total $1494 \kappa r$ of active substances to the area of one hectare of crops. Such antropine the chemical load on the environment leads to significant unwanted side effects. Examples of this type of pollution is now a fact in countries with intensive Aghanim production, for example the Netherlands.

Traditional approaches to farming will not paid considerable attention to issues of species diversity and biological activity of complexes of soil organisms. The issue of creating the necessary level of effective fertility is tradition solved by use of mineral fertilizers. The application of mineral fertilizers to exercise more 
convenient and faster compared with using organic fertilizers. This practice, apart from positive aspects, and has significant shortcomings. High norms of mineral fertilizers, particularly nitrogen, significantly affecting the complexes of living organisms topsoil. Most forms of nitrogen fertilizers are physiologically acidic and acidifying the soil solution. High concentrations inhibit the biological activity of many forms of soil microflora, i.e. topsoil as result of this chemical pressure is transform from a complex and elaborate complex of living organisms in the substrate for placement of mineral nutrient compounds[15].The practice of wide application of mineral fertilizers shows that the coefficients of absorption of nutrients cultivated plants have traditionally been relatively low. Nitrogen compounds in the first year after their introduction into the soil of cultural plants used by $50-60 \%$ and phosphorus compounds by $20-25 \%$, potassium compounds for $60-70 \%$ of the value of their input. Given the fact that nitrogen compounds in the soil is narukami, most of them easily moves from the plow layer in pedroto water, or washed sediments in rivers and lakes[16]. The presence of organic compounds in water bodies leads to their so-called eutrophic pollution and the "bloom" of water. Underground water of the high concentration of active ingredients of fertilizers become unfit for drinking and human use[17].

The urgent question is how you can generate high level of soil effective fertility for the implementation of high productive potential of modern varieties and hybrids of cultivated plants on arable land without the use of high norms of mineral fertilizers. Is it possible in nature for achieving a high level of fertility effective without negative side effects, primarily environmental pollution? Possible. The standard maximum natural optimization of the conditions of the growing season green plants are tropical rainforests[18]. Of course, such conditions are impossible to create in the moderate climatic zone on the planet, but to evaluate and take advantage of the unique nature and creatively apply the principles of nature for constructing such high-performance and ecological systems is advisable.The formation of significant amounts of organic matter as result of intensive processes of photosynthesis complex of different systematic position of the plants in natural tropical plant communities requires adequate supplies of the factors of life. In tropical forests in constant circulation is a large volume of organic nutrients, primarily compounds of nitrogen, phosphorus and potassium. It is their high application rates often create environmental problems in intensive farming systems. However, in tropical natural complexes of living organisms do not have these problems[19].

In ecosystem of tropical rainforest, biogenic compounds are constantly in circulation and their alienation is not happening. A leaf that has completed its active operation, it immediately falls off and used as a nutrient substrate reducent of organisms: fungi, bacteria, insects, and other mineralizers of organic matter. Mineral components in green plants used again for their vital processes. Large stock of organic substances in the territory only less than $2 \%$ of the total volume is in a free state in soil layer. Their main volume is always in the form of organic substances in various organisms[20].Attempts to convert the area of tropical forest into arable land to traditional cultivation of crops of cultivated plants, fails. The destruction of the perfect dynamic complex of living organisms in tropical forests leads to a decrease of species diversity of life and violation of circulation of the organic components in the system. The alienation of such substances with the crops and deprives the already relatively poor soil organic matter. These soils over a few years turn into a dead Laterano breed, which is not capable of surviving plants. Erosion completes the destruction of the territory, which began[21].

Accordingly, for the successful functioning of arable land in the zone of tropical rainforests deliberate to simulate the crop system interaction and circulation of energy and substances between the environments living organisms, soils and plants producers. The alienation of significant amounts of organic compounds with a crop requires the payment of adequate amounts of getting into the soil with organic matter, which is the source of the energy needed for existence of organism's heterotrophs.

Life proves the imperfection of agricultural lands, which forms man to arable land compared to natural phytocoenoses in all climatic zones of the planet. Most clearly, this discrepancy is revealed in the tropics. Humid tropical forest, as was described previously, is the most complex, sophisticated and high-performance ecosystems on the planet[22]. This is sort of a benchmark that clearly demonstrates the perfection of nature. The temperature regime throughout the year there is stabilnim and favourable for successful vegetation many kinds of green plants. Temperature variations by season traditionally makes up to $10^{\circ} \mathrm{C}$ and is in the range of $24 \ldots 34^{\circ} \mathrm{C}$. Daily temperature fluctuations within $5 \ldots 7^{\circ} \mathrm{C}[23]$. Heating the soil surface in the wide-row crops agriculture even in temperate latitudes during the summer months can reach $40^{\circ} \mathrm{C}$ and $70^{\circ} \mathrm{C}$ even. This temperature regime leads to drying of the upper arable layer, affects the activity of soil microflora, activity of root systems and ground parts of cultivated plants. Plants for many days are in a state of temperature dis-stress, significantly reduce the assimilative processes, including photosynthesis and the yields of crops[24]. In a humid tropical forest soil surface is in deep shadow and projective closed leaves of plants. Accordingly, its temperature is almost the same as the temperature of the surface layer of air $23 \ldots 34^{\circ} \mathrm{C}$. This temperature regime is favorable to the vegetation of green plants and vigorous activity completes the living organisms of the soil[25]. 
World of plants is most fully able to realize their productive potential in the conditions of the tropics. The development of plants from other climatic zones of the planet, it is the realization of adaptive capacity due to the partial reduction of the biological potential. Such adaptation cannot all kinds. Most tropical plants die even when the temperature drops to $5 \ldots 7^{\circ} \mathrm{C}$ heat[26]. Their enzymes are not in condition for such a temperature level to ensure the implementation of necessary biochemical reactions in cells.

At the same time, many species of plants from the tropics were able to move not only in the subtropics and in temperate latitudes of the planet. For example, almost all representatives of the Botanical family Hvilya (Aristilochiaceae) are typical tropical species. However, this kind of as kirkason common - Aristolochia clematitis L. not only successfully adapted to the temperate latitudes, but has become one of the worst weeds in crops of cultivated plants[27].

An important factor in determining the level of biological productivity of biocenoses, is the intensity of the light flux, primarily of far energy and its absorption by plants. In the conditions of the tropics, the intensity of the incident flux of light in the afternoon hours exceeds $1 \mathrm{~kW} / \mathrm{m}^{2}$ per hour. In the temperate zone the intensity of the light flux is less, but even here she comes up to $0.8 \mathrm{kWh} / \mathrm{m}^{2} /$ year. In the rainforest range of plants of different species absorbs the light energy of the sun very thoroughly[28].If the incident flux of light energy to eliminate the amount of albedo and the energy absorbed by plants, to the soil surface in a tropical forest comes not more than 1\%[29]. The crops of cultivated plants in agroecosystems is able to achieve similar performance energy absorbing headlight for a certain period of the growing season of crops: corn throwing Volta, sugar beets after closing leaves between the rows, etc. However, during the previous and subsequent periods of organogenesis through the insufficient area of leaves per unit area of crops, loss of cultural plants from 50 to $94 \%$ of the incident energy flux of the headlight. This energy is not only lost, it will be used on forming and development of plants of the weed competitors. Unlike agricultural lands, tropical rain forest has the highest level of absorption of energy of headlight during the whole year with 12 hours of daylight. To approximate the magnitude of the indices of absorption of the flow of energy of headlight in agroecosystems of the temperate zone to the biological indicators of the reference system is possible by forming pollicove of crops, in which the periods of formation of the maximum leaf area in plants of different species of cultivated plants are not the same.Tropical rain forest and a specific microclimate.

In tropical rain forests, falls and more than $2500 \mathrm{~mm}$ of rainfall during the year. Their distribution may be different. There are regions with periods of rain and relatively dry periods when the rains fall at intervals of 2-4 days instead of daily. In other regions, rain falls regularly during the year. High relative humidity and powerful daily the dew that sometimes reaches several millimeters, the required level of moisture of the soil and air.Indicators of relative humidity show a direct impact on the mode of operation of the stomata on the leaves of plants and the intensity of the processes of photosynthesis. In the vegetation layers of the rain forest level of relative humidity is traditionally in the range of $76-100 \%$. A large area of the leaf surface of the plants ensures evaporation of large amounts of water on a day - up to $18 \mathrm{~mm}$ Moisture that evaporated traditionally falls new rains. The water cycle acts almost like perpetual motion, only with a constant additional flow of energy from the Sun. Water shortages, plants in the tropical forests never feel[30].On arable lands of the temperate latitudes of the planet, the rainfall is much less. In different regions of the country drops from 370 to $700 \mathrm{~mm}$ of water per year. About $1 / 3$ of this amount comes in cold winter and 2/3 in the warm season. The intervals between rainfall in recent decades to grow and often reaches 60 to 90 days. Precipitation traditionally come in the form of intense thunderstorm rainfall, which complicates their rational use by crops.

In the warm period of the year in the territory of our country the relative humidity varies in a wide interval: from 16 to $95 \%$. The longest period is in the range of $30-60 \%$. This level of relative humidity contributes to active transpiration of water by plants. In the Steppe zone the combination of high temperature air with low relative humidity and strong winds (above $5-8 \mathrm{~km} / \mathrm{h}$ ) leads to intensive evaporation from the soil and transpiration of water by plants from 3 to $8 \mathrm{~mm}$ of moisture per day.Under conditions of high temperature and low provide of plants the moisture of the implementation of the processes of photosynthesis difficult or impossible. The water deficit in plants is the result of intensive transpiration and the difficulty of absorption of water by the root system from the soil. In conditions of water deficit in plants stomata on a leaf plate is closed and the access of carbon dioxide in the tissue chlorenchyma stops. In such a situation, the synthesis of organic substances in plants is blocked. Vegetation in such conditions leads to low biological productivity of agrocenoses.Insufficient relative height of agricultural crops, traditionally from 0.5 to $3.0 \mathrm{~m}$, and to cultivated plants complicates the possibility of forming favorable for vegetation, and the processes of photosynthesis microclimate on arable land.

The tropical rainforest layers of the leaves of green plants placed in the ground atmospheric layer height on average up to 50 meters. Leaf area of different species placed very efficiently in height and horizontally, that provides the maximum possible illumination.In agrocenoses of plants of the same species of crops and even varieties (variety or hybrid) form its foliage at the same height and almost all at the same time. So to ensure their efficient lighting virtually impossible. An example can be wheat, corn or soy.Modern intensive technology of cultivation of agricultural crops traditionally offer a certain level of specialization of farms. 
This specialization to the fore is not the laws of biology and agronomy, and economic considerations and market conditions. As a result, the crops any crop: soybean, corn or sunflower occupy the lion's share of arable land in the regions. People consciously form the major food base for the complex of pests and diseases of dominant cultures [31, 32]. The massive build-up of pests, accumulation of infection and specialized types of weeds require intensive measures to protect crops from adverse effects of harmful organisms. Protection in intensive technologies of cultivation of agricultural crops traditionally carried out using pesticides. Such massive use of xenobiotics does not only protect crops, but also contaminate the harvest and negatively affect the environment.

The crops of agricultural plants traditionally sprayed from 3 to 15 times with insecticides and fungicides, and in orchards and vineyards up to $20-25$ times or more[33]. Traditional approaches to protecting crops against pests to reduce chemical load on the environment is difficult. The need for new scientific solutions to the problem.

High level of biological diversity in tropical rain forests and the presence of trophic linkages and the relationship ensures the maintenance of homeostasis biological means and does not require intervention in the processes of regulation of the person.Forest basins of the Amazon and the Orinoco cover about $20 \%$ of the area of tropical forests on the planet, and focus on its spaces nearly $40 \%$ of species diversity of the planet. Biological species has created a unique ecological communities that are not only capable of self-regulation, the maximum use of environmental factors, as well as ensure very high biological productivity and a positive influence on the entire planet[34, 35].Life proves the futility of the technocratic approach to the issues of increasing food production for the population of the planet. Intensive technology leads to intensive destruction of the environment, a reduction in species diversity of nature, pollution of water, soil and air. In those approaches, the nature loses the ability to compensate for the destructive influence of human activity that may cause disaster for humanity itself.

To substantially increase the production volumes of the agricultural sector, science must develop a fundamentally new methodological approaches to the use of arable land and the technologies of growing different species of plants. As a kind of benchmark can be used a perfect natural Pezenas and highly productive wet tropical forests. We don't need to copy the conditions of the tropics, however, we have the opportunity to creatively use and adapt to the conditions of the temperate zone of the planet those rational decisions that have created nature in the formation of relationships such perfect natural complex.There are opportunities and they deserve for creative development in different directions. For example, the amount of moisture coming from the regions of the country really cultivated plants are used not rationally, sometimes only $30-40 \%$. All the rest, the unproductive losses. Ways to reduce unnecessary loss is a real possibility to boost the supply of moisture to the crops of cultivated plants.

Most transpiration of water by leaves of cultivated plants under conditions of vegetation in the Steppe under the influence of high air temperatures, low relative humidity and strong winds may be significantly reduced by purposeful formation of microclimate on arable land. In the Steppe zone impossible to form a favorable microclimate in the surface layer of air height of 50 meters, but decrease the speed of the wind in it at a height of several meters is quite real as using wind belts, and the formation of a strip of crops of different height. To reduce the intensity of erosion processes is the formation of areas covered with vegetation in the form of cultivated pastures, hayfields, etc.For significant revitalization of the complex of living organisms in the topsoil, which should ensure easy accessibility of organic compounds for plants without significant leaching and pollution in temperate climatic zone, it is appropriate to increase and regular supply of organic matter in topsoil in optimal moisture indicators, acidity of soil solution.

\section{Conclusions:}

1. A mechanism of intensification of technologies of cultivation of agricultural crops to achieve the maximum biological productivity of agricultural production through futile considerable negative side effects of chemical xenobiotics on the environment, decreased species diversity and destruction of natural plant communities.

2. Intensive varieties and cultivation technology (creation of $10 \mathrm{t} / \mathrm{ha}$ of wheat) amount to only about $60 \%$ of the average level of biological productivity of tropical rain forests which has no environmentally undesirable side effects).

3. The modeling of tropical forests in the temperate climatic zone of nemola, however, the use of the principles vmod componets tropical biocenoses will allow to develop highly productive crops and do not destroy do not pollute the environment.

4. The proposed review vimag a more detailed analysis of all components of the interaction between the components of animate and inanimate nature and creative presanna the identified principles in the practice of modern agricultural production. 


\section{Bibliography}

1. A. Newman Lungs of our planet, Moscow: Mir 1989 - 333s.

2. Vernadsky V. S. The biosphere and noosphere /Vernadsky And W. M.: 1991.-S. 139-150.

3. Larssen L. M. and ozernye International river basins of Asia: conflicts and ways of cooperation / L. M. Larssen, S.In.Zherelina //Geography and natural resources. No. 2. -2010. -C11-14.

4. Sokolov M. S. Biospherology V. S.Vernadsky is no alternative strategy for human survival in the twentyfirst century./ M. S. Sokolov /Agrochemistry. 2012 -No. 7. -P. 3-9.

5. Bega S. V. Ecological agriculture. / S. W. Begay, Lviv: New world, 2009. - 428c.

6. Baker S. D. the advantages and disadvantages of no-till / H.D.Baker, K. E. Saxton, G. Ritchie I/Agronomy, 2011, Vol 1. - P. 15-16.

7. Dehodjuk E. G., By prof S. E Ecological - technological exploitation / Dehodjuk E. G., S. E. By prof. -Kiev: ECMO, 2006. - 306c.

8. Dehodjuk E. G. Between organic and mineral fertilizers / E. G. Dehodjuk // The Ukrainian Farmer. - 2013. -C. $68-70$.

9. Medvedev V. V. the Zero tilling of the soil in European countries. In.Medvedev - Kharkiv, 2010. - 200C.

10. Rational use of land resources / V. F. Saiko, G. A. Mazur, E. G. Dehodjuk, S. E. By prof. a. / / Scientific basis of agroindustrial virobnictva in Forest-steppe zone of Ukraine, - Kyiv: agricultural science. 2010. S. $106-272$.

11. Sytnik K. M. the State of the soil and the future of mankind / K. M. Sytnyk, V. M. Bagnat, - Agrarian Bulletin of NAS of Ukraine, 2008, № 8. - S. 3-27.

12. Ermolaev N. M. Regularities of formation of the water regime in the crop rotation on chorizema left-Bank Forest steppe / N. M.Ermolaev, L. I. Shilina, V. D. Litvinov. -K.: Bulletin of agrarian science- 2008, №6. S. 13-17.

13. Transformation of humus under the influence of crop rotations and fertilizers/ N. M.Ermolaev, D.Litvinov, L. I. Shilina, V. M. Ermolaeva //Interdepartmental thematic scientific collection "Agriculture" -K.V.D. "Edelweiss". -2012. - vol. 84. - S. 25-32.

14. Ivashchenko A. A. the decor in agroprocessed/ Ivaschenko, A. A. -K.: Institute of sugar beet UAAS, 2001. -240c.

15. Saiko V. F. System of soil treatment in Ukraine/ V. F. Sykes, A. M. Malienko - K.: publishing house "ECMO", -2007. - 44C.

16. Medvedev V. V. Monitoring of soils of Ukraine. Concept. Results. Tasks. (2nd per. and EXT. edition) / V. V. Medvedev -Kharkov: K. P. "Urban typography", 2012. - 563c.

17. Kaminski, V. F. Culture green manuring. The scientific basis for effective application of green fertilizers in farms of different forms of ownership / ed. by E. G. by prof. [C. Y. Bulygin, F. V. Kaminsky, S. E. By prof and others] - K.: -2013. - 79c.

18. The 6th International Weed Science Congress, Hangzhou, China17-22 June 2012, Proceedings.

19. Timiryazev K. A. Selected works, vol 1/K. A. Timiryazev. -M.: Publishing House of Agricultural, 1957.

20. Adamenko T. assessment of the current agro-climatic conditions and trends of their changes in Ukraine in the period of global warming / T. Adamenko, N. Kulbida, A. Prokopenko // Minsterstvo of agrarian policy and food of Ukraine, Ukrainian hydrometeorological center of MOE of Ukraine. -K.: 2009. -12C.

21. Babich A. A. Selection, production, trade and use of soybeans in the world /A. A. Babich, A. A. BabichCoastal.-M.: agricultural science. -2011. -548c.

22. Intensification technologies wirewound corn - guarantee the stabilization of yields on $90-1004 / \mathrm{ha}$ : recommendations for action / by F. V. Cherenkov, V. S. Tsikov, Would. in.Zabecki, etc.] Dnepropetrovsk: si Institute of agriculture of steppe zone NAAS, 2012. - 30C.

23. Saiko V. F. Biological basis for the formation of the consumption of winter wheat / V. F. Saiko. - K.: agricultural science - 2011. - -P. 24-32.

24. Saiko V. F. Problems and ways of accumulation and use of biological nitrogen in modern agriculture of Ukraine / V. F. Sykes, in proc. Sciences. proceedings of the NSC "WITH NAAN" - a Special edition. - 2006. P. 8-13.

25. Fedorenko V. P. Actual issues of protection of crops/ W. P. Fedorenko, S. V. Rethman// Quarantine and plant protection. - 2009. - №3. -S. 1-5.

26. Triebel S. A. Zonal use of resistant varieties. Efficient and environmentally friendly crop protection of winter wheat against most common pests. / S. A. Triebel, M. V. Rethman // Quarantine and plant protection. 2008. - No. 4 . -S. 6-9.

27. Koval V. P. to Stop the madness in the spraying / Quarantine and plant protection, 2011. - No. 10. P. 26-28.

28. Turekhanov A. N. Biosphere -biogeocenological research in the sea of Azov. -M.: Nauka, 1975. P. 5-19. 
29. Kurgak V. G. Meadow agroprocessed / U. G. Kurgak .-K.: DIA, -2010. -374c. 30. Bunning E. Der tropische Regenwald. Verstandliche Wissenschaft. Bd. 56, Berlin, Gottingen, Heidelberg, 1956.

31. Knapp R. Die Vegetation von Nord \& Mittelamerika and der Hawaii - Inseln as Stuttgart, 1965.

32. Muller - Schneider P. Verbreitunsbiologie (Diasporologie) der Blutenpflanzen. 2 Ed. Veroff. Geobotan. 61 Institut Rubel, 1977 (Zurich).

33. Strategy and tactics of plant protection vol. 2, ed. V. P. Fedorenko - K.: Alfa-stevia LTD, 2015. -784c.

34. P. W. Richards, The tropical rain - forest. Cambridge, 1952.

35. Walter H. Vegetationszonen and Stuttgart Klima, 1970. 